\title{
A practical guide to cryptorchidism for the primary care physician
}

\author{
JENNIFER MARGARET LOVIN ${ }^{A-F}$, NAZIH KHATER ${ }^{A-F}$, JOHN A. MATA A-F \\ ORCID ID: 0000-0002-6846-0009 ORCID ID: 0000-0003-0511-0965
}

Department of Urology, Louisiana State University Health - Shreveport, Shreveport, Louisiana, USA

A - Study Design, B - Data Collection, C - Statistical Analysis, D - Data Interpretation, E - Manuscript Preparation, F - Literature Search, G - Funds Collection

Summary Cryptorchidism, also known as undescended testis, affects 3-5\% of full term male infants at birth and $23 \%$ of preterm or low birth weight infants. Current guidelines recommend that all boys with cryptorchidism without testicular descent by 6 months of age be referred to an appropriate specialist for evaluation, with surgery preferably performed by 18 months. We aim to examine areas of controversy still being debated by reviewing published articles, in order to provide primary providers with a practical guide to diagnosis and management of the undescended testis.

Our review examined published articles from 2000 to 2018, related to undescended testes, and their management. 32 articles were reviewed from 2000 to 2018 and showed with a high level of evidence that failure of testicular descent by 6 months of age (gestational) should prompt referral to an appropriate specialist. Physical exam is crucial. The main concerns for patients with cryptorchidism are the increased risk of testicular cancer and sub fertility. Routine use of scrotal ultrasound is not recommended in the evaluation of cryptorchidism. Diagnostic laparoscopy serves to confirm the presence of an intra-abdominal testicle. Surgical intervention within 18 months of age is imperative. Cryptorchidism should be corrected surgically between 6 months and 18 months of age. Early detection with diagnostic laparoscopy is the standard of care for treatment of palpable, undescended testis.

Key words: cryptorchidism, physicians, primary care, orchiopexy.

Lovin JM, Khater N, Mata JA. A Practical guide to cryptorchidism for the primary care physician. Fam Med Prim Care Rev 2019; 21(1): 78-82, doi: https://doi.org/10.5114/fmpcr.2019.82983.

\section{Background}

Cryptorchidism (undescended testis; UDT) is defined as failure of testicular descent into the anatomic position within scrotum, and can be further categorized into congenital (extrascrotal testicular location at birth) or acquired (scrotal position at birth with spontaneous ascent to an extrascrotal position) [1, 2]. This condition should be differentiated from the retractile testis, which is within the scrotal position but easily retracts towards the inguinal canal due to an overactive cremasteric reflex [2]. Likewise, a vanishing testis is present initially during development but later disappears (potentially from spermatic cord torsion or vascular accident) [1-3] and testicular agenesis, which refers to a testis that was never present during development [2].

Cryptorchidism affects $3-5 \%$ of full term male infants at birth and $23 \%$ of preterm or low birth weight infants [4]. Spontaneous testicular descent occurs in $76 \%$ of males by 6 months of age. However, descent after 6 months is uncommon and should prompt referral to a qualified specialist [4]. Acquired cryptorchidism has a prevalence of $1-7 \%$ and peaks around age 8 [5]. It is thought to originate from aberrant androgen signaling and is often seen in males with proximal hypospadias [1]. While a wide range of factors have been implicated in the development of cryptorchidism, contemporary data suggests that family history, prematurity and low birth weight increase the risk of UDT [6]. Syndromic cryptorchidism is associated with disease processes that reduce androgen production or action such as disorders of sexual development, as well as Kleinfelter's syndrome, Down syndrome, prune belly syndrome, cerebral palsy, myelomeningocele and posterior urethral valves [2].

Early diagnosis and treatment of cryptorchidism is associated with a decreased risk of testicular volume loss, testicular cancer and may confer a lower risk of subfertility [26, 28-31].
Therefore, prompt referral to a surgical specialist for evaluation and management of UDT is essential.

The aim of our study was to review current literature, in order to provide primary providers with a practical guide to diagnosis and management of undescended testes, with the long-term goals of reducing the delay in diagnosis and treatment and improving quality of care to all boys with this condition.

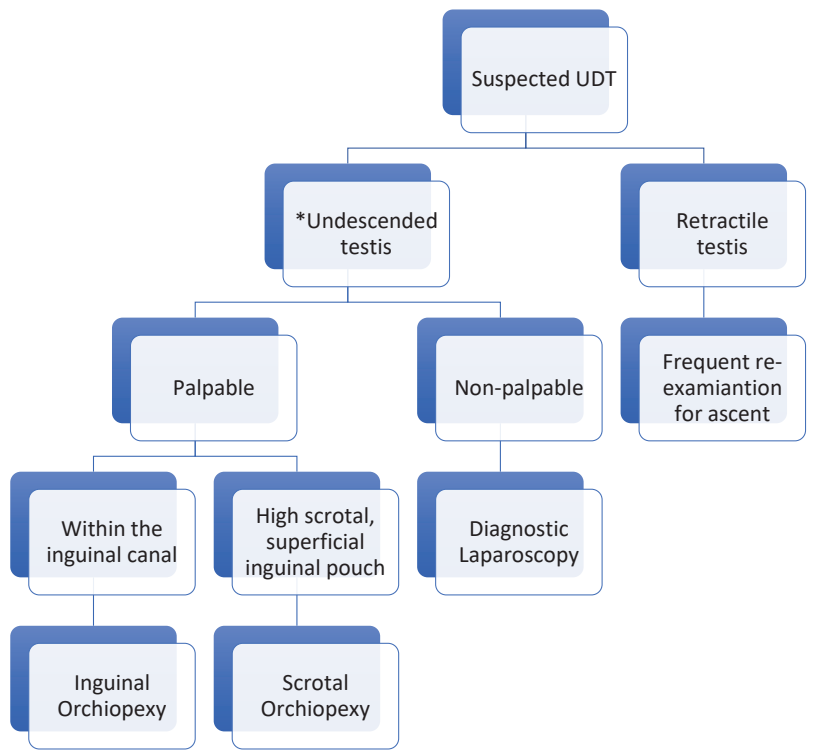

Figure 1. Algorithm for evaluation and management of UDT

*Referral to a specialist should occur in patients 6 months of age with UDT or with acquired cryptorchidism 


\section{Objectives}

With this review, we aim to address areas of controversy still being debated regarding evaluation and management of cryptorchidism. We conducted an extensive literature review of published articles related to cryptorchidism, with the goal of providing primary providers with a practical and evidence-based guide to diagnosis and management of the undescended testis.

\section{Material and methods}

We conducted a review of published articles from 2000 to 2018, related to undescended testes, and their management, including areas of controversy.

A literature search was performed using PubMed and MEDLINE as the primary databases. The main search terms were undescended testes and cryptorchidism alone and in combination with embryology, physical examination, surgical and non-surgical management. Selection criteria included judgment about the novelty and importance of the studies and their relevance for the well-informed primary care physician. We also searched articles in reference list identified by this search strategy. The primary outcome of our review was to clarify the most appropriate age for surgical intervention, as well as diagnostic tools to add to the primary care physician's armamentarium

\section{Results}

We identified 32 articles in our search, from 2000 to 2018, that were reviewed. An overview of the embryology, physical examination and prognosis are paramount prior to clarifying updated guidelines and areas of controversy.

\section{Embryology}

Cryptorchidism results from a failure of normal, embryologic testicular descent, which occurs in two phases [7]. The first phase, referred to as the transabdominal phase, occurs from 8-15 weeks of life, and is regulated by insulin like factor 3 . The second phase, referred to as the inguinoscrotal phase, occurs from 25-30 weeks gestation and is androgen dependent. Arrest in descent can occur anywhere along this pathway, resulting in a cryptorchid or ectopic testis $[6,8]$.

\section{Shortcomings in current management of undescended testes}

Current urologic guidelines recommend that all boys with cryptorchidism without spontaneous testicular descent by 6 months of age be referred to an appropriate specialist for evaluation, with surgical intervention performed by 18 months [1]. However, despite these recommendations, contemporary data suggests that there is delay in diagnosis and treatment in many patients [9-12]. Williams et al. found that $48 \%$ of patients had repair at a median age of 4 years and $64 \%$ underwent orchiopexy after age 2 years [13]. Almost $70 \%$ of boys with UDT in the series underwent surgical repair at least 6 months later than the recommended age. Additional factors, such as race and insurance status, also influenced the timing of surgical repair. African American and Hispanic boys, as well as those with public or no insurance, experienced a delay in diagnosis and treatment of cryptorchidim [14]. Despite these guidelines, some primary care providers may lack confidence in diagnosing UDT and may benefit from having an evidence-based approach to evaluation and management of this condition. A poll of German pediatric practitioners found that $61 \%$ of respondents were insufficiently informed about current guidelines [15]. Accordingly, Kim et al. concludes that future guidelines should be applicable to primary care physicians as well as surgical specialists, and more widely disseminated to address current knowledge gaps [16].

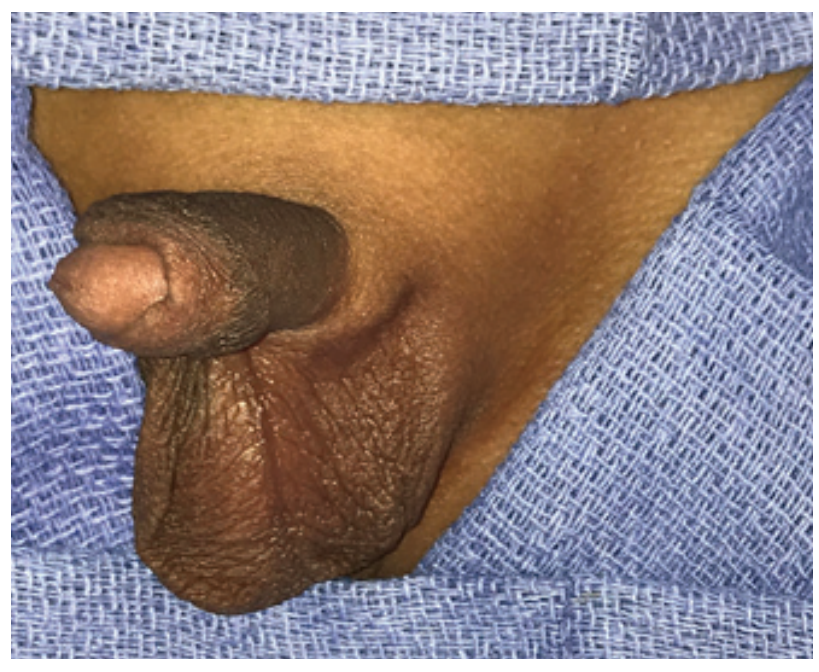

Figure 2. Undescended testis in a 2 year-old male

Pre-pubertal boy with physical examination findings of scrotal asymmetry and hypoplastic scrotum suggestive of a left sided undescended testis.
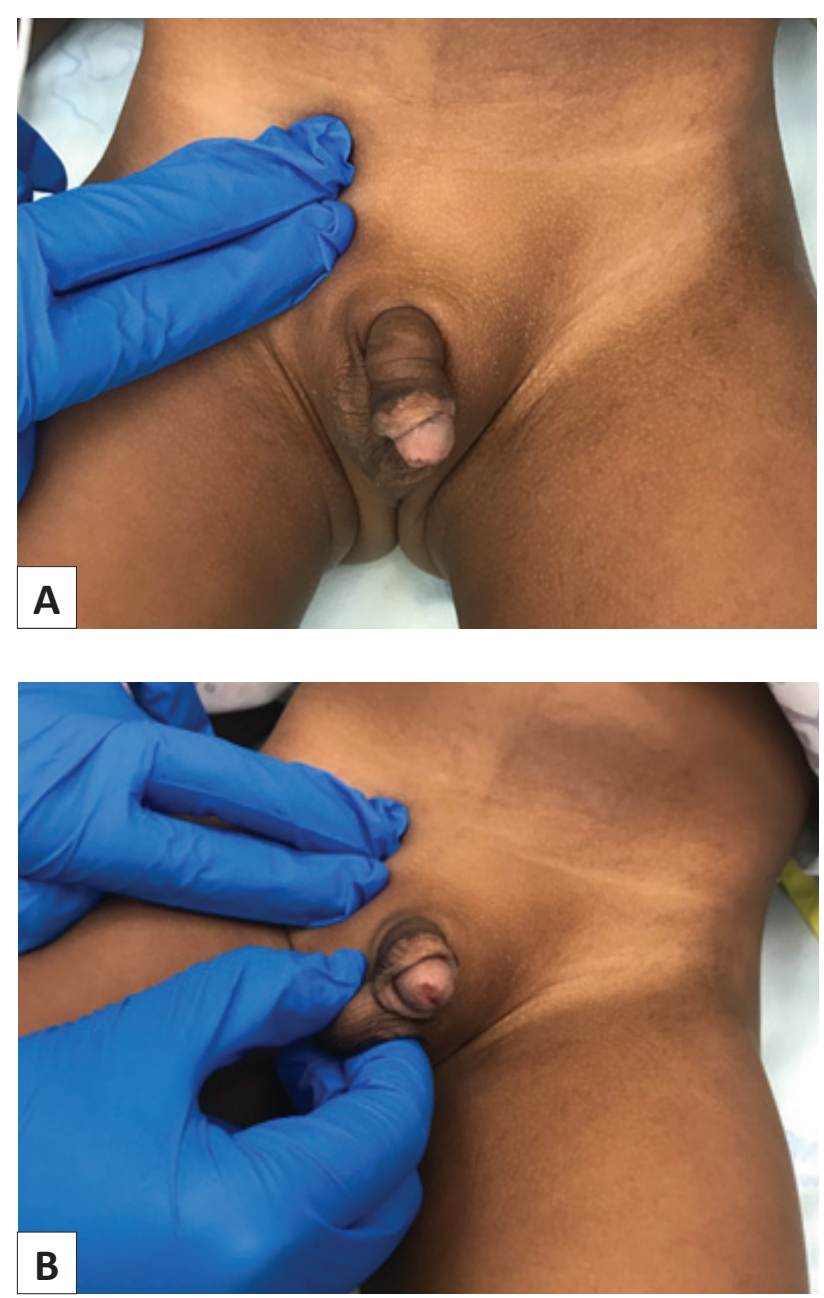

Figure 3. Examination of the cryptorchid testis

A (top). Examination should begin by sliding one hand from lateral to medial along the inguinal canal. A sensation of a "pop" may identify the underlying testis within the inguinal canal.

B (bottom). Gentle pressure is applied to the cryptorchid testis within the inguinal canal with one hand just superior to the testis. The other hand is used to apply gentle traction to bring the testis into the scrotum. 


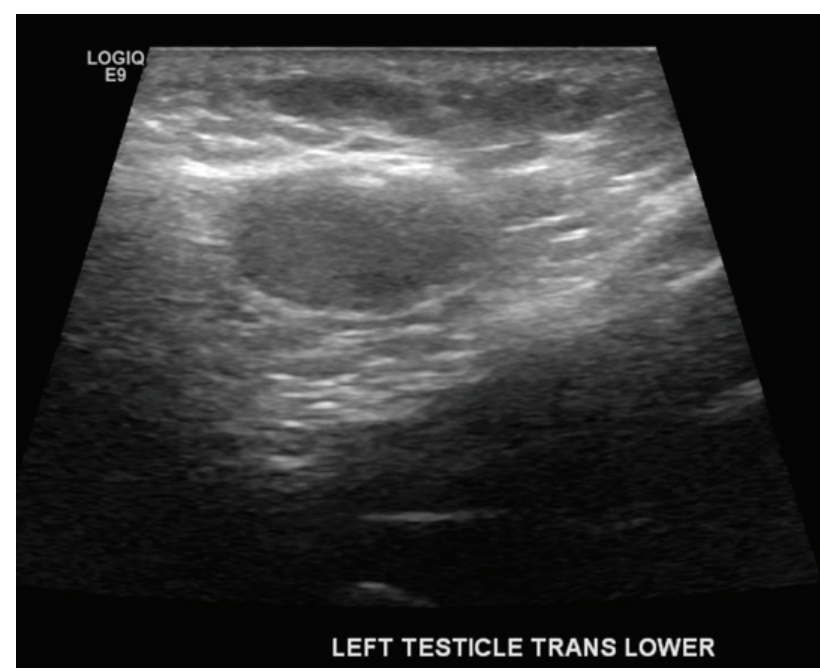

Figure 4. Inguinal ultrasound identifying cannalicular testis

While routine use of scrotal ultrasound is not recommended for the evaluation of undescended testes, it may be useful in select cases. Inguinal ultrasound demonstrates cryptorchid testis within the inguinal canal in an obese 5 year-old boy.

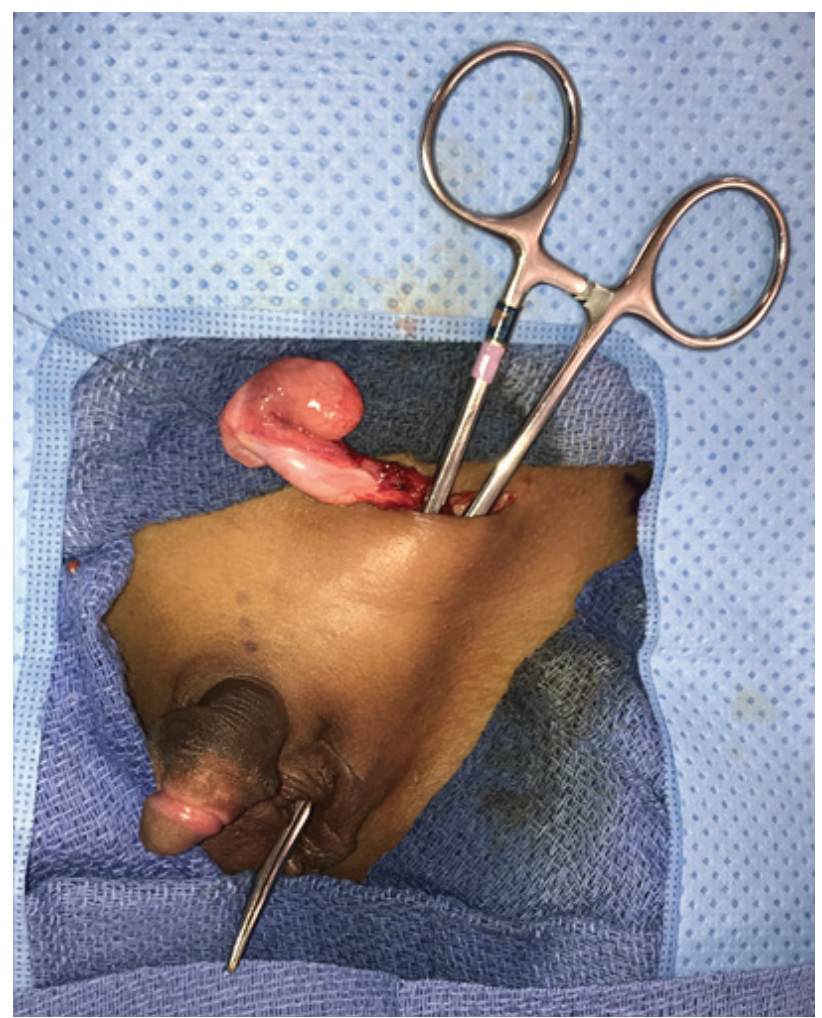

Figure 5. Inguinal orchiopexy for undescended testis

2 year old with an inguinal undescended testis with intraoperative delivery from the inguinal canal to the superficial scrotal pouch, where testis will undergo orchiopexy.

\section{Physical examination}

UDT can be located anywhere along the pathway of embryologic descent (intra-abdominal, cannalicular, superficial inguinal pouch, upper scrotum) or in an ectopic location (peripenile, contralateral scrotal, perineal, femoral), with $70-74 \%$ of UDT being palpable $[1,17]$. Of those that are not palpable, $33 \%$ are found within the inguinal-scrotal area, $33 \%$ are intra-abdominal, and $33 \%$ are vanishing or absent [18]. Spontaneous testicular descent routinely occurs by a gestational age of 6 months [1].
AUA guidelines recommend that practitioners perform a genitourinary (GU) examination at every well child visit until puberty and males with retractile testes be monitored annually for acquired cryptorchidism, given the increased risk of spontaneous testicular ascent in this population. UDT that persist at 6 months of age (corrected for gestational age) should prompt referral to an appropriate specialist $[1,2]$.

Examination should be conducted in both the supine and standing positions, if possible, with legs crossed to inhibit the cremasteric reflex. A cross-legged position can assist in testicular identification in overweight boys. A warm examination room, warm hands, patient distraction, and repeated exams may assist in clarifying testicular location.

Inspection for scrotal asymmetry should be performed, as hypoplasia of the ipsilateral scrotum may suggest UDT. Examination of the affected testis should follow. This is best performed by sliding one hand from lateral to medial along the inguinal canal and a sensation of a "pop" may identify a testis within the inguinal canal. Gentle pressure may be applied with one hand just cranial to the testis that is identified within the canal and the other hand may be used to apply gentle traction to bring the testis into the scrotum. It is important to attempt to hold the testis within the scrotum for approximately one minute, which will cause fatigue of the cremaster reflex. If the testis remains within the scrotum after release, it is considered retractile, while immediate ascent into the inguinal canal constitutes an undescended testis. Other details, such as size, texture and associated findings (e.g. hernia or hydrocele) should be noted $[2,11,19]$.

Examination of the contralateral testis may reveal compensatory hypertrophy in the setting of a contralateral vanishing testis [3]. Rarely, a testicular nubbin can be palpated within the inguinal canal. Bilateral UDT are highly suspicious for disorders of sexual development (DSD) and definitely necessitate referral to a specialist, with strong consideration given to obtaining a simultaneous karyotype and hormonal evaluation [1, 32]. Details to be noted during examination of the penis include penile size, presence and location of urethral meatus, and prepucial abnormalities such as a dorsal hood deformity. Circumcision should be deferred if DSD is suspected.

\section{Use of adjunctive imaging modalities}

While the routine use of ultrasound (US) by primary care physicians to diagnose cryptorchidism is common, there is no compelling evidence to support its use [20,32]. In a survey by Tasian et al., $67 \%$ of respondents ordered imaging as part of pre-surgical evaluation and $96 \%$ used US [21]. Pediatricians in practice for less than 20 years (OR 3.43) or in non-academic practices (OR 3 ) were more likely to use imaging modalities in their evaluations. As rationale for its routine use, respondents cited the belief that imaging identifies non-palpable testes, reassures families, and assists the surgeon with preoperative planning. However, US fails to correctly identify testicular location in the vast majority of cases and is not generally used in preoperative planning [22]. In fact, the sensitivity and specificity of US for localization of a non-palpable testis is $45 \%$ and $78 \%$, respectively [23]. While MRI has greater sensitivity and specificity for determining testicular location, its expense and sedation requirement precludes widespread use. Therefore, the American Urological Association (AUA) Guidelines recommend against the use of US in the evaluation of cryptorchidism [1].

\section{Treatment}

The gold standard treatment of cryptorchidism is orchiopexy. Also known as ochidopexy, this term refers to the surgical procedure used to relocate an undescended testis into the scrotum and affix it using sutures. This can be done through a variety of approaches, depending on testicular location. Testes with 
a high scrotal location, or within the superficial inguinal pouch, are often amenable to a scrotal approach, while palpable cannalicular testes are typically treated with an inguinal orchiopexy. Diagnostic laparoscopy is the preferred technique for evaluation of non-palpable testes, which can identify an intra-abdominal or vanishing testis, and guide subsequent intervention [24]. Laparoscopy is performed using three 3 to $5 \mathrm{~mm}$ trocars: one camera port, which is placed at the umbilicus and two working ports at each McBurney's point ( $1 / 3$ the distance from the anterior superior iliac spine to the umbilicus). The peritoneum is searched extensively for a vas deferens and spermatic vessels, which will lead to the cryptorchid testis. The finding of a blind ending vas and vessels represents testicular absence (vanishing testis). If the testis is identified and there is sufficient vascular length to reach the scrotum, laparoscopic orchiopexy is performed. In the event that the testis lacks sufficient mobility secondary to tethering spermatic vessels, a two-stage Fowler Stevens approach is performed. The first stage involves clipping the spermatic vessels and the second stage, performed 6 months later following creation of collateral blood supply to the cryptorchid testis, involves relocation of the testis to the scrotum. The success rate of laparoscopic single stage orchiopexy is reported to range from 87-97\% and the 2-stage Fowler-Stephens orchiopexy demonstrates a success rate of $63-96 \%$. The greatest risks following laparoscopic orchiopexy include varying degrees of testicular atrophy and secondary testicular ascent $[2,20]$.

\section{Prognosis}

Patients with cryptorchidism, even following surgical correction, are at increased risk of testicular cancer and subfertility $[3,32]$. Boys with UDT demonstrate higher luteinizing hormone (LH) and follicle-stimulating hormone (FSH) levels, as well as lower sperm concentrations and hormone levels [25]. Oligospermia is present in $44 \%$ and azoospermia in $35 \%$ of subjects. There is an inverse relationship between age at surgical intervention, testicular volume and semen concentration [26]. Fortunately, abnormal semen parameters do not necessarily translate into infertility in the majority of unilaterally cryptorchid men [2]. Lee et al. found that the paternity rate in unilaterally cryptorchid men is $89.5 \%$, which is similar to fertility rate of $94 \%$ in the general population [27]. UDT also confers a 3-6 times increased risk of testicular cancer in the ipsilateral testis and a slight increased risk in the contralateral testis $[28,29]$. While older literature cited no difference in risk of testicular malignancy with timely orchiopexy, contemporary data suggests that prepubertal orchiopexy decreases the risk of testis cancer, but does not decrease the risk to match that of normal controls $[30,31]$. Prepubertal orchiopexy is associated with a 2-6 fold relative risk reduction of testicular cancer as compared to postpubertal orchiopexy. This underlines the importance of monthly self-testicular exams beginning at puberty to allow early identification and treatment of testicular malignancy.

\section{Conclusions}

Cryptorchidism is defined as failure of testicular descent into the anatomic position within the scrotum. Testicular descent occurs by 6 months of age in most patients, and is more common in preterm or low birth weight infants. Failure of testicular descent by 6 months of age (gestational) should prompt referral to an appropriate specialist, with surgical intervention within 18 months. The routine use of scrotal ultrasound is not recommended in the evaluation of cryptorchidism. Diagnostic laparoscopy is used to confirm the presence of an intra-abdominal testicle. The main concern for patients with cryptorchidism remains the increased risk of testicular cancer and sub fertility.

Acknowledgements. We thank our colleagues from Louisiana State University Health who provided insight and expertise that greatly assisted the creation of this manuscript.

Source of funding: This work was funded from the authors' own resources.

Conflicts of interest: The authors declare no conflicts of interest.

\section{References}

1. Kolon TF, Herndon CD, Baker LA, et al. Evaluation and treatment of cryptorchidism: AUA guideline. J Urol 2014; 192(2): $337-345$.

2. Barthold J, Hagerty J. Etiology, diagnosis, and management of the undescended testis. In: Wein A, Kavoussi L, Partin A, Peters C, eds. Campbell-Walsh urology. 11th ed. Philadelphia: Elsevier; 2016: 3430-3452.

3. Hutson JM, Vikraman J, Li R, et al. Undescended testis: what paediatricians need to know. J Paediatr Child Health 2017; 53(11): 1101$-1104$.

4. Ghirri P, Ciulli C, Vuerich M, et al. Incidence at birth and natural history of cryptorchidism: a study of 10,730 consecutive male infants. $J$ Endocrinol Invest 2002; 25(8): 709-715.

5. Acerini $\mathrm{CL}$, Miles HL, Dunger DB, et al. The descriptive epidemiology of congenital and acquired cryptorchidism in a UK infant cohort. Arch Dis Child 2009; 94(11): 868-872.

6. Gurney JK, McGlynn KA, Stanley J, et al. Risk factors for cryptorchidism. Nat Rev Urol 2017; 14(9): 534-548.

7. Favorito LA, Costa SF, Julio-Junior HR, et al. The importance of the gubernaculum in testicular migration during the human fetal period. Int Braz J Urol 2014; 40(6): 722-729.

8. Barteczko KJ, Jacob MI. The testicular descent in human. Origin, development and fate of the gubernaculum Hunteri, processus vaginalis peritonei, and gonadal ligaments. Adv Anat Embryol Cell Biol 2000; 156: 1-98.

9. Lim LY, Nah SA, Lakshmi NK, et al. Undescended testis: level of knowledge among potential referring health-care providers. J Paediatr Child Health 2015; 51(11): 1109-1114.

10. Cho A, Ball M, Read K, et al. Educational survey of regional general practitioner's management of paediatric patients with undescended testis. J Pediatr Urol 2016; 12(3): 151.e1-7, doi: 10.1016/j.jpurol.2015.11.010.

11. Zundel S, Blumenstock G, Herrmann-Werner A, et al. Undescended testis? How best to teach the physical examination. J Pediatr Urol 2016; 12(6): 406e1-406e6.

12. Bruijnen CJ, Vogels HD, Beasley SW. Age at orchidopexy as an indicator of the quality of regional child health services. J Paediatr Child Health 2012; 48(7): 556-559.

13. Williams K, Baumann L, Shah A, et al. Age at orchiopexy for undescended testis in the United States. J Pediatr Surg 2017, doi: 10.1016/j. jpedsurg.2017.10.020.

14. Savoie KB, Bachier-Rodriguez M, Schurtz E, et al. Health disparities in the appropriate management of cryptorchidism. J Pediatr 2017; 185: 187-192.e1, doi: 10.1016/j.jpeds.2017.03.003.

15. Boehme P, Geis B, Doerner J, et al. Shortcomings in the management of undescended testis: guideline intention vs. reality and the underlying causes - insights from the biggest German cohort. BJU Int 2018; 122(4): 644-653, doi: 10.1111/bju.14171. 
16. Kim JK, Chua ME, Ming JM, et al. A critical review of recent clinical practice guidelines on management of cryptorchidism. J Pediatr Surg 2017; 53(10): 2041-2047, doi: 10.1016/j.jpedsurg.2017.11.050.

17. Shoukry M, Pojak K, Choudhry MS. Cryptorchidism and the value of ultrasound. Ann R Coll Surg Eng/ 2015; 97(1): 56-58.

18. Berger C, Haid B, Becker T, et al. Nonpalpable testes: ultrasound and contralateral testicular hypertrophy predict the surgical access, avoiding unnecessary laparoscopy. J Pediatr Urol 2018; 14(2): 163.e1-163e7, doi: 10.1016/j.jpurol.2017.10.010.

19. Braga LH, Lorenzo AJ. Cryptorchidism: a practical review for all community healthcare providers. Can Urol Assoc 2017; 11(1-2 Suppl. 1): S26-S32, doi: 10.5489/cuaj.4343.

20. Shepard CL, Kraft KH. The nonpalpable testis: a narrative review. J Urol 2017; 198(6): 1410-1417.

21. Tasian GE, Yiee JH, Copp HL. Imaging use and cryptorchidism: determinants of practice patterns. J Urol 2011; 185(5): $1882-1887$.

22. Hartigan S, Tasian GE. Unnecessary diagnostic imaging: review of the literature on preoperative imaging for boys with undescended testes. Transl Androl Urol 2014; 3(4): 359-364.

23. Tasian GE, Copp HL, Baskin LS. Diagnostic imaging in cryptorchidism: utility, indications, and effectiveness. J Pediatr Surg 2011; 46(12): 2406-2413.

24. Chan KW, Lee $\mathrm{KH}$, Wong $\mathrm{HY}$, et al. Use of laparoscopy as the initial surgical approach of impalpable testes: 10-year experience. World $J$ Clin Pediatr 2015; 4(4): 155-159.

25. Rohayem J, Luberto A, Nieschlag E, et al. Delayed treatment of undescended testes may promote hypogonadism and infertility. Endocrine 2017; 55(3): 914-924.

26. Tseng CS, Chiang IN, Hong CH, et al. Advantage of early orchiopexy for undescended testis: analysis of testicular growth percentage ratio in patients with unilateral undescended testicle. Sci Rep 2017; 7(1): 17476, doi: 10.1038/s41598-017-17825-w.

27. Lee PA, Coughlin MT. The single testis: paternity assessment after presentation as unilateral cryptorchidism. J Urol 2002; 168(4 Pt 2): 1680-1682.

28. Lip SZ, Murchison LE, Cullis PS, et al. A meta-analysis of the risk of boys with isolated cryptorchidism developing testicular cancer later in life. Arch Dis Child 2013; 98(1): 20-26.

29. Akre O, Pettersson A, Richiardi L. Risk of contralateral testicular cancer among men with unilaterally undescended testis: a meta analysis. Int J Cancer 2009; 124(3): 687-689.

30. Walsh TJ, Dall'Era MA, Croughan MS, et al. Prepubertal orchiopexy for cryptorchidism may be associated with lower risk of testicular cancer. J Urol 2007; 178(4 Pt 1): 1440-1446.

31. Pettersson A, Richiardi L, Nordenskjold A, et al. Age at surgery for undescended testis and risk of testicular cancer. N Engl J Med 2007; 356(18): 1835-1841.

32. Braga LH, Lorenzo AJ, Romao RLP. Canadian Urological Association-Pediatric Urologists of Canada (CUA-PUC) guideline for the diagnosis, management, and follow up of cryptorchidism. Can Urol Assoc J 2017; 11(7): E251-60.

Tables: 0

Figures: 5

References: 32

Received: 7.08.2018

Reviewed: 15.08.2018

Accepted: 27.08.2018

Address for correspondence:

John A. Mata, MD

Department of Urology

Louisiana State University Health - Shreveport

1501 Kings Highway

Shreveport, LA 71130

USA

Tel.: (318) 675-5601

E-mail: jmata@Isuhsc.edu 